\title{
Research on the Opening of Adverse Drug Reaction Data in the EU
}

\author{
Yiwen Ding1, Yongfa Chen1,2*, Pengcheng Liu ${ }^{1,2}$ \\ ${ }^{1}$ School of International Pharmaceutical Business, China Pharmaceutical University, Nanjing, China \\ ${ }^{2}$ NMPA Key Laboratory for Drug Regulatory Innovation and Evaluation, Institute of Regulatory Science, China Pharmaceutical \\ University, Nanjing, China \\ Email: *cyf990@163.com
}

How to cite this paper: Ding, Y.W., Chen, Y.F. and Liu, P.C. (2021) Research on the Opening of Adverse Drug Reaction Data in the EU. Open Journal of Preventive Medicine, $11,278-287$.

https://doi.org/10.4236/ojpm.2021.116022

Received: June 3, 2021

Accepted: June 26, 2021

Published: June 29, 2021

Copyright (c) 2021 by author(s) and Scientific Research Publishing Inc. This work is licensed under the Creative Commons Attribution International License (CC BY 4.0).

http://creativecommons.org/licenses/by/4.0/

\section{(c) (i) Open Access}

\begin{abstract}
Systematically analyze the composition of post-marketing adverse drug reaction data and the open mode in the EU, and summarize its characteristics. EU post-marketing ADR data is open to six categories of stakeholders: EMA, EC, medicines regulatory authorities in EEA member states, healthcare professionals and the public, Marketing Authorization Holders, academia, WHO and medicines regulatory authorities in third countries. The EU has implemented hierarchical opening for ADRs, with different levels containing different data and facing different stakeholders. Openness is divided into active and passive openness. In opening up data, the EU complies with relevant personal data protection laws to protect the privacy of individuals. The EU's post-marketing adverse drug reaction data openness is characterized by a combination of data openness and privacy protection, active and passive openness, and a hierarchy of data openness. It is hoped that this can provide a reference for the opening up of post-marketing adverse drug reaction data in China.
\end{abstract}

\section{Keywords}

Adverse Drug Reactions, Open Data, European Union

\section{Introduction}

With the development of information technology, data is becoming a new driving force for social innovation in the 21st century. Data is the raw material of information, and information is the result of data processing. Data opening is the release of the original records, unprocessed and uninterpreted data with no clear meaning, which is an upgrade and leap forward of information opening [1]. Compared with information disclosure, data opening has reached a new height in both breadth and depth [2]. Data opening can not only improve the 
transparency of the government, but also promote the reuse of data by the society and create political, economic and social value [3]. In 2005, the European Commission launched the European Transparency Initiative in order to eliminate the monopoly of public information and create reuse of public information [4]. In order to promote the implementation of the European Transparency Initiative and to better protect public health, the EMA issued the EU Pharmacovigilance Data Open Policy in July 2011 to make available data on adverse drug reactions after marketing [5]. In December 2011, the European Commission officially released "Open Data: An Engine for Innovation, Growth and Transparent Governance", and the EU began to implement the data openness strategy [6], which provides a stronger guarantee for the opening of ADR data. The opening of ADR data after marketing has promoted the scientific research of pharmacovigilance in EU, contributed to the warning of ADR, clinical medication guidance and public medication safety guarantee [7], and also promoted the scientific supervision of EU regulatory authorities [8] [9] [10].

\section{Composition of ADR Data in the EU}

EudraVigilance Post-Authorisation Module (EVPM) is responsible for collecting individual case safety reports on all authorized drugs. EU classifies post-marketing ADR reports into four types, namely, spontaneous reports, research from study, and others ${ }^{1}$ (reports of spontaneous observation or research cited in the literature with uncertain sources) and the reports of type not indicated by the original sender. The EU ADR data structure follows the guidelines for individual safety reporting issued by the International Coordinating Committee for Technical Requirements for Medicinal Products for Human Use (ICH E2B (R3)), which consists of identity data and case data and contains 272 data fields. Among them, the identity data consists of the identification of the individual security report, the main information source, the sender of the individual security report, the literature reference, and the research identification. Case data consists of patient characteristics, responses/events, test and procedure results relevant to the patient study, drug information, and narrative case summaries.

\section{Objects and Levels of ADR Data Opening in EU}

At present, EU post-marketing ADR data is available to six types of stakeholders: the EMA, the European Commission, and medicines regulatory authorities in EEA member states, healthcare professionals and the public, Marketing Authorization Holders, academia, WHO and medicines regulatory authorities in third countries.

The EU has implemented a hierarchical opening for ADR data, with three levels: Level 1, Level 2 (2A, 2B, 2C) and Level 3. Different levels contain different

${ }^{1}$ The EU does not classify ICSRs in the literature separately. If the ICSRs in the literature are derived from spontaneous observation, they are classified as "spontaneous reports". If it comes from a study, it is classified as "report from study"; If it is unclear from the literature report whether or not the case(s) cited are spontaneous observation or arises from a study, then it is classified as "other". 
data and target different stakeholders. The level 1 dataset is open to all stakeholders. According to the needs of stakeholders and different pharmacovigilance obligations, level 2 is further divided into three sub-levels: $2 \mathrm{~A}, 2 \mathrm{~B}$, and $2 \mathrm{C}$. The level 2A dataset is targeted at the MAH and academia to support the MAH in fulfilling its pharmacovigilance obligations and to support research that promotes public health. The $2 \mathrm{~B}$ level dataset is oriented to the MAH to support the MAH's signal validation activities. Level $2 \mathrm{C}$ data sets are targeted at WHO and third country pharmaceutical regulatory authorities to support public health protection outside the European Community. The Level 3 data set contains all Individual Case Safety Report (ICSR) data, and is fully open to the EMA, the EC and the pharmaceutical regulatory authorities of the Member States to help them fulfil their responsibility to protect public health. In addition, the EU is fully open to the Marketing Authorization Holder (MAH) for the data contained in ICSRs that are sent to the EU Pharmacovigilance Database by the MAH or that are generated from the medical literature monitoring activities of the EMA to help MAH better fulfill pharmacovigilance obligations. Table 1 summarizes the level of openness of ADR data in the EU.

\section{EU Adverse Drug Reaction Data Open Mode}

According to the types of ADR reports and the levels of ADR data openness, the EU has different ways of data openness for various stakeholders. Generally speaking, there are two ways, which include proactive disclosure of ICSR data and reactive disclosure of ICSR data.

Table 1. Openness levels for ADR data in the EU.

\begin{tabular}{|c|c|c|c|c|}
\hline \multirow{2}{*}{\multicolumn{2}{|c|}{ The open level }} & \multicolumn{3}{|c|}{ Table Column Head } \\
\hline & & Describe & The data fields & Stakeholder oriented \\
\hline \multicolumn{2}{|c|}{ Level 1} & $\begin{array}{l}\text { Common subset of } \\
\text { ICSR data }\end{array}$ & 53 & $\begin{array}{l}\text { Healthcare professionals } \\
\text { and the public; } \mathrm{MAH} ; \\
\text { Academia; WHO; } \\
\text { Medicines regulatory } \\
\text { authorities in third } \\
\text { countries }\end{array}$ \\
\hline \multirow{3}{*}{ Level 2} & $2 \mathrm{~A}$ & $\begin{array}{l}\text { Extended subset } \\
\text { of ICSR data }\end{array}$ & 228 & MAH; Academia \\
\hline & $2 \mathrm{~B}$ & $\begin{array}{l}\text { Extended subset of ICSR } \\
\text { data, including case } \\
\text { narratives }\end{array}$ & 231 & $\mathrm{MAH}$ \\
\hline & $2 \mathrm{C}$ & $\begin{array}{l}\text { Extended subset of ICSR } \\
\text { data }\end{array}$ & 134 & $\begin{array}{l}\text { WHO; Medicines } \\
\text { regulatory authorities } \\
\text { in third countries }\end{array}$ \\
\hline \multicolumn{2}{|c|}{ Level 3} & Open all ICSR data & 272 & $\begin{array}{l}\text { EMA, EC, and medicines } \\
\text { regulatory authorities in } \\
\text { EEA member states; MAH }\end{array}$ \\
\hline
\end{tabular}




\subsection{Proactive Disclosure of ICSR Data}

- For spontaneous report of Level 1 data, the EU is proactively open to all stakeholders. Each interested party does not need authorization or registration, but can directly access relevant data through a specific ADR portal [11], and can search by drug name or drug active ingredient as the search term to obtain a corresponding analysis report. Each report is made up of seven sections, each presented as a chart. Part 1: The number of individual cases. The total number distribution of cases can be shown by age, sex, geographical source, and type of reporter. Part 2: The number of individual cases received over time, which shows the number of cases received each month over the past 12 months in terms of months. Part 3: The number of individual cases by EEA countries. The total number of cases submitted by each country/region and the relative frequency distribution are shown by EEA country/region. Part 4: The number of individual cases by reaction group. According to the MedDRA lexicon, reaction group is a classification of adverse reactions to drugs, such as heart disease, gastrointestinal disease, immune system disease, etc. The number of cases involved in each response group can be shown separately by age group, gender, severity, type of reporter and geographical origin. Part 5: the number of individual cases for a selected reaction group. The number of cases, such as heart disease, can be viewed according to the selected response group. The number distribution can be shown by age group and gender, type of reporter, and geographical source. Part 6: the number of individual cases for selected reaction. Based on selected responses, such as tachycardia in heart disease, the quantitative distribution can be shown by age group and sex, type of reporter, and outcome. Part 7: The line listing. According to the filtering conditions, the corresponding ADR reports and some ADR data in the reports are displayed. Visitors can download all the case reports and data in PDF, HTML, Excel, PowerPoint, or Web Archive formats. And the data can also be output in Excel, CSV, Tab Delimited, XML. Various data output methods provide great convenience for visitors, especially researchers.

- For level 1 and 2A data on post-marketing adverse reaction reports and for data on adverse reaction reports submitted by MAHs, the EU is proactively open to MAHs. Access personnel need to be authorized. After registration, the EU Pharmacovigilance Authorizer (Headquarters Level) and agents authorized person who are appointed by the EU Pharmacovigilance Authorizer can access this data through the Pharmacovigilance Data Management System (EVWEB).

- For post-marketing adverse reaction reports at level $2 \mathrm{C}$ data, the EU is actively open to WHO-UMC. Access personnel need to be authorized. Data access is available to WHO-UMC authorized personnel through the Application Ports (API) between WHO-UMC and EMA.

- The EU has taken the initiative to open up all data on post-marketing adverse 
reactions reported by the EMA, the EC and the regulatory authorities of the Member States. Access personnel need to be authorized. Authorized personnel of the EMA, EC and the regulatory authorities of each Member State may access the data through the network reporting application and data analysis system of the EU Pharmacovigilance System.

\subsection{Reactive Disclosure of ICSR Data}

- MAH can apply for access to Level 2B data in the post-marketing adverse event report. When the MAH needs to perform signal verification and validation, the $2 \mathrm{~B}$ level data can be accessed for all reporting requests of the EVMP module. After the submission of a formal request and the signing of a confidentiality agreement, Access to the data in the report at level 2B can only be made by authorized personnel, including the EU Pharmacovigilance Authorizer (headquarters level) and agents and authorized personnel appointed under the strict responsibility of the EU Pharmacovigilance Authorizer.

- Research institutions may apply for access to level 2A data in post-marketing adverse event reports. When research institutions are conducting research aimed at promoting public health and improving procedures to protect public health, an application can be made to the EMA for access to the Level 2A data set of post-marketing adverse events reports. At the time of the study application, the EMA should be informed of the main study questions, the study methodology, the public health implications of the findings, and the names and contact information of the persons established by the research institution responsible for protecting the pharmacovigilance database study data. In addition, the data access request should also describe the privacy checks that the institution intends to conduct prior to publication, to prevent the disclosure of personal data and to prevent the possible re-identification of data subjects (e.g., patients, reporters). After the application is submitted and the confidentiality agreement is signed, the personnel designated by the research institution can access this part of data.

- Third-country regulators may apply for access to level 2C data in post-listing adverse reaction reports. When the EMA receives an application for a visit from a pharmaceutical regulatory authority in a third country, for example when assessing safety issues related to the drug, it provides a level $2 \mathrm{C}$ data set of post-marketing adverse reaction reports. The visitor should be authorized, and the designated person of the pharmaceutical regulatory authority of the third country should have the access right.

Table 2 provides the openness of ADR data in the EU.

\section{Personal Privacy Data Protection Measures}

In the opening up of ADR data, the EU strictly complies with the personal data protection regulations, Reg (EU) 2018/1725 and Reg (EU) 2016/679. The 
Table 2. Openness of ADR data in the EU.

\begin{tabular}{|c|c|c|c|c|c|}
\hline \multirow[b]{2}{*}{ Stakeholders } & \multicolumn{5}{|c|}{ Table Column Head } \\
\hline & The report type & $\begin{array}{c}\text { The open } \\
\text { level }\end{array}$ & Open mode & Open way & $\begin{array}{l}\text { Whether authorization is } \\
\text { required to access data }\end{array}$ \\
\hline $\begin{array}{l}\text { EC, EMA and } \\
\text { medicines regulatory } \\
\text { authorities in EEA } \\
\text { member states }\end{array}$ & $\begin{array}{l}\text { EVPM }^{2} \\
\text { reports }\end{array}$ & Level 3 & Proactive & EVWEB $^{3}$, EVDAS $^{4}$ & $\begin{array}{l}\text { The authorized personnel of EC, } \\
\text { EMA and Drug regulatory agencies of } \\
\text { the Member States }\end{array}$ \\
\hline $\begin{array}{l}\text { Healthcare } \\
\text { professionals and } \\
\text { the public }\end{array}$ & $\begin{array}{l}\text { Spontaneous } \\
\text { reports }\end{array}$ & Level 1 & Proactive & ADR Web Portal & No request \\
\hline \multirow{4}{*}{ MAH } & $\begin{array}{l}\text { Spontaneous } \\
\text { reports }\end{array}$ & Level 1 & Proactive & ADR Web Portal & No request \\
\hline & \multirow[b]{3}{*}{ EVPM reports } & Level 1 & Proactive & & $\begin{array}{l}\text { The EU Pharmacovigilance Authorizer } \\
\text { (headquarters level) or the EU }\end{array}$ \\
\hline & & $\begin{array}{l}\text { Level 2A } \\
\text { Level } 3^{* 5}\end{array}$ & $\begin{array}{l}\text { Proactive } \\
\text { Proactive }\end{array}$ & EVWEB, EVDAS & $\begin{array}{l}\text { Pharmacovigilance Authorizer is } \\
\text { strictly responsible for the appointed } \\
\text { agents and authorized personnel }\end{array}$ \\
\hline & & Level 2B & Reactive & Apply to the EMA & $\begin{array}{l}\text { Access may only be made by the EU } \\
\text { Pharmacovigilance Authorizer } \\
\text { (headquarters level) or by agents and } \\
\text { authorized personnel appointed under } \\
\text { the strict responsibility of the EU } \\
\text { Pharmacovigilance Authorizer after the } \\
\text { submission of the request and the } \\
\text { undertaking of confidentiality }\end{array}$ \\
\hline \multirow{3}{*}{ Academia } & $\begin{array}{l}\text { Spontaneous } \\
\text { report }\end{array}$ & Level 1 & Proactive & ADR Web Portal & No request \\
\hline & EVPM reports & Level 2A & Reactive & Apply to the EMA & $\begin{array}{l}\text { After the research application is } \\
\text { submitted and the letter of } \\
\text { confidentiality is signed, the } \\
\text { personnel designated by the } \\
\text { research institution can visit the site }\end{array}$ \\
\hline & $\begin{array}{l}\text { Spontaneous } \\
\text { report }\end{array}$ & Level 1 & Proactive & ADR Web Portal & No request \\
\hline WHO & EVPM reports & Level 2C & Proactive & $\begin{array}{l}\text { The API of } \\
\text { WHO-UMC and } \\
\text { EMA }\end{array}$ & $\begin{array}{l}\text { Authorized personnel from the World } \\
\text { Health Organization (WHO) } \\
\text { Monitoring Centre in Uppsala }\end{array}$ \\
\hline Medicines regulatory & $\begin{array}{l}\text { Spontaneous } \\
\text { report }\end{array}$ & Level 1 & Proactive & ADR Web Portal & No request \\
\hline $\begin{array}{l}\text { authorities in } \\
\text { third-country }\end{array}$ & EVPM reports & Level 2C & Reactive & Apply to the EMA & $\begin{array}{l}\text { Person appointed by the drug } \\
\text { regulatory authority of the } \\
\text { third-country }\end{array}$ \\
\hline
\end{tabular}

${ }^{2}$ Reports collected by the post-marketing monitoring module of the pharmacovigilance database include spontaneous reports, research reports, other reports (cited in the literature with uncertain sources of spontaneous observations or studies), and reports of a type not indicated by the original sender.

${ }^{3}$ EudraVigilance web reporting application. An interface to a pharmacovigilance data management system that allows registered users to create, send, and view ICSRs.

${ }^{4}$ EudraVigilance web reporting application. The EU Pharmacovigilance Data Analysis System is dedicated to the safety testing activities of the EU Pharmacovigilance, mainly focusing on the signal detection and evaluation of ICSRS.

5“*”: ICSRs sent by the MAH to the EU Pharmacovigilance Database, or ICSRs generated from the medical literature monitoring activities carried out by the EMA. 
personally identifiable data of the patients involved in the adverse event data and the reporter were kept confidential.

In order to better protect personal privacy and data security, all stakeholders should also abide by the following provisions when accessing adverse reaction data. 1) Information on EU pharmacovigilance data is contained in their privacy statement on pharmacovigilance activities; 2) The confidentiality of ICSRS and the personal data of the parties are protected in accordance with applicable personal data protection laws; 3) Appropriate technology and measures are in place to ensure that data and personal information processed will not be accessed, disclosed, disseminated, altered or destroyed or accidentally lost without authorization or illegally; 4) If a breach of security regulations results in accidental or unlawful destruction, loss, tampering, unauthorized disclosure or access to data held or generated by the EU Pharmacovigilance Database, or otherwise protected personal data, notify EMA immediately.

In addition, the EU stipulates that research institutions and $\mathrm{MAH}$ can only access $2 \mathrm{~B}$ and $2 \mathrm{C}$ data after signing the corresponding confidentiality agreement. Where the MAH ensures that ICSR level $2 \mathrm{~B}$ data subjects are not identified, associated, or locked, and ensure that Level $2 \mathrm{~B}$ data is used for signal management purposes specified in Module 6 of the GVP, or in pharmacovigilance evaluation procedures such as periodic safety report updates specified in Module 7 of the GVP, or in the referral or signal evaluation procedures of the PRAC under the conditions specified in this Commitment and in accordance with applicable data protection legislation. The research institution undertakes not to identify, contact, or lock the $2 \mathrm{~A}$ data subject and not to transfer the data to any third party. In addition, when investigators conduct studies using adverse event data, a copy of the article using ICSR data should be provided to the EMA at least 5 working days prior to publication [12].

\section{The Characteristics of ADR Data Openness in EU}

- Data opening and privacy protection are equally important. The protection of personal data and privacy is the premise of ADR data opening. In the process of Data opening, the EU abides by the general Data Protection regulations, and also makes reference to the opinions of the European Data Protection Supervisor, so that all stakeholders can access the adverse reaction Data to an appropriate degree under the premise of protecting personal privacy.

- Hierarchical opening of ADR data. Different stakeholders have different demands for adverse reaction data. For example, the public has a low demand for adverse reaction data and has different levels of cognition of adverse reactions. Excessive data opening may cause unnecessary panic of the public. However, MAH has to fulfill the corresponding pharmacovigilance obligations and responsibilities, while EMA, EC and national drug authorities have to fulfill the responsibility of protecting public health, so there is a great de- 
mand for ADR data. In addition, due to the detailed nature of the information, fully opening up adverse reaction data can lead to the re-identification of potential data subjects. Therefore, according to the different interests and needs of different stakeholders and the compliance with the relevant personal data protection laws, the EU implements the hierarchical opening of ADR data.

- Combine active opening and passive opening. The EU believes that the active and passive openness of adverse reaction data is complementary, and that the combination of the two openness approaches puts the EU transparency principle into practice. Active disclosure of adverse reaction data to the maximum extent, subject to compliance with EU personal data protection laws, and can minimize the need for temporary and passive disclosure of data at the request of individuals. This not only facilitates the acquisition of adverse reaction data by various stakeholders, but also reduces the workload of regulatory departments caused by the application visits to a certain extent and avoids the occupation of a large number of administrative resources.

\section{Conclusions}

In August 2015, the State Council issued the Outline of Action to Promote the Development of Big Data, which proposed the goal of building a unified and open platform for government data in China, and took the lead in moderately opening public data to the society in medical and health fields [13]. In 2018, the Ministry of Industry and Information Technology (MIIT) and others released the Pilot Work Programme for the Opening of Public Information Resources, proposing to carry out pilot projects for the opening of public information resources in five places-Beijing, Shanghai, Zhejiang, Fujian and Guizhou-in which healthcare, public safety, education and culture, science and technology innovation and other areas were listed as key public information resources to be opened. Despite the intensive promulgation of policies to promote data openness, adverse drug reaction data is still not included in government data openness projects. So, at present, ADR data in China is still shared among regulatory agencies [14], and the public is still at the level of information disclosure, which has not gone deep into the data level, and the public's right to know and right to life and health cannot be well protected.

The opening of ADR data in the EU not only improves the transparency, but also meets the needs of various stakeholders for ADR data, strengthens the communication of ADR information, promotes the utilization of ADR data, and protects public health better. Its ADR data opening mode is relatively mature, which ensures the right of all stakeholders to obtain ADR data, while protecting trade secrets and personal privacy, so as to better balance the demands of all stakeholders. China can learn from the EU's experience of opening up adverse drug reaction data to better implement the opening up of China's adverse drug reaction data, specifically there are four experiences, 1) Improve China's person- 
al privacy data protection laws and regulations. In addition to the opening up of adverse drug reaction data, personal privacy data should also be effectively protected, so as to coordinate the conflict between personal privacy and data opening, and provide support for the opening up of adverse drug reaction data. 2) The implementation of a combination of reactive and proactive open access. For non-sensitive data, open up the data proactively, and for sensitive data, open up the data reactively, and give visitors the right to submit applications to access the data. 3) Open the adverse drug reaction data in a hierarchical manner. Firstly, the stakeholders involved in the opening of adverse drug reaction data should be clarified, and the needs of each stakeholder should be clarified, after which different levels of data sets should be set according to the needs of stakeholders, and different data should be opened for different stakeholders, which is conducive to the coordination of conflicts of interest while meeting the needs of each stakeholder 4) Build an ADR web portal similar to that of the EU. Provide a search function to facilitate visitors to quickly locate the data they want. In addition, enhance the visualisation of search results in the web portal and increase data output methods to improve the ease of use of the data, thereby improving the effectiveness of opening up ADR data.

\section{Conflicts of Interest}

The authors declare no conflicts of interest regarding the publication of this paper.

\section{References}

[1] Shandong Provincial People's Government Website (2020-08-18/2021-03-28) From Government Information Disclosure to Open Government Data. http://www.gov.cn/xinwen/2020-08/18/content 5535596.htm

[2] Fu, X.W. and Zheng, L. (2013) A Review of Domestic Research on Open Government Data. E-Government, No. 6, 8-15.

[3] Fu, X.W. and Zheng, L. (2020) The Value of Open Government Data: Research Progress and Prospects. Library and Intelligence Work, 64, 122-132.

[4] Cao, L. (2013) Big Data Innovation: A Study of the EU's Open Data Strategy. Intelligence Theory and Practice, 36, 118-122.

[5] EMA (2011-08-23/2021-03-15) EudraVigilance Access Policy for Medicines for Human Use.

https://www.ema.europa.eu/en/documents/other/eudravigilance-access-policy-med icines-human-use en.pdf

[6] European Commission (2011-12-12/2021-03-27) Open Data-An Engine for Innovation, Growth and Transparent Governance.

https://ec.europa.eu/digital-single-market/en/node/61043

[7] Postigo, R., Brosch, S., Slattery, J., et al. (2018) EudraVigilance Medicines Safety Database: Publicly Accessible Data for Research and Public Health Protection. Drug Safety, 41, 665-675. https://doi.org/10.1007/s40264-018-0647-1

[8] Innovative Medicines Initiative (2015) PROTECT: Pharmacoepidemiological Research on Outcomes of Therapeutics by a European Consortium. 
[9] Candore, G., Slattery, J., Kurz, X., et al. (2015) Revision of Guidance on Screening for Adverse Drug Reactions in Eudravigilance. Drug Safety, 38, 964-965.

[10] European Medicines Agency (2016-12-19/2021-03-20) Screening for Adverse Reactions in EudraVigilance.

http://www.ema.europa.eu/docs/en GB/document library/Other/2016/12/WC5002 18606.pdf

[11] EMA (2021-03-22) Adrreports.eu. https://www.adrreports.eu/en/disclaimer.html

[12] EMA (2019-08-23/2021-03-12) European Medicines Agency Policy on Access to EudraVigilance Data for Medicinal Products for Human Use.

https://www.ema.europa.eu/en/documents/other/european-medicines-agency-polic y-access-eudravigilance-data-medicinal-products-human-use-revision-4 en.pdf

[13] State Council (2015-09-05/2021-04-02) Outline of Action to Promote the Development of Big Data.

http://www.gov.cn/zhengce/content/2015-09/05/content 10137.htm

[14] Wang, T., Wang, D., Fan, Y., et al. (2018) Functional Upgrading and Reflections on the EU Pharmacovigilance Database. China Pharmacovigilance, 15, 31-33+38. 